\title{
Erratum zu: Religiöse Identitäten und Vorurteil in Deutschland und der Schweiz - Konzeptionelle Überlegungen und empirische Befunde
}

\author{
G. Pickel · A. Liedhegener $\cdot$ Y. Jaeckel $\cdot$ A. Odermatt $\cdot$ A. Yendell
}

Online publiziert: 15. Juni 2020

(C) Springer Fachmedien Wiesbaden GmbH, ein Teil von Springer Nature 2020

\section{Erratum zu:}

\section{Z Religion Ges Polit 2020}

https://doi.org/10.1007/s41682-020-00055-9

Leider war im Originalbeitrag die englische Übersetzung des Titels nicht korrekt. Der englische Titel muss wie folgt lauten:

Religious Identities and Prejudice in Germany and Switzerland-Conceptual considerations and empirical findings.

Die Online-Version des Originalartikels ist unter https://doi.org/10.1007/s41682-020-00055-9 zu finden.

G. Pickel $(\bowtie) \cdot$ A. Liedhegener $\cdot$ Y. Jaeckel $\cdot$ A. Odermatt $\cdot$ A. Yendell Theologische Fakultät, Institut für Praktische Theologie, Abteilung für Religions- und Kirchensoziologie, Universität Leipzig, Martin-Luther-Ring 3, 04109 Leipzig, Deutschland E-Mail: pickel@rz.uni-leipzig.de 